\title{
The ring-shaped thermal field of Stefanos crater, Nisyros Island: a conceptual model
}

\author{
M. Pantaleo and T. R. Walter \\ Department 2, Physics of the Earth, Helmholtz Centre Potsdam, GFZ German Research Centre for Geoscience, \\ Potsdam 14473, Germany \\ Correspondence to: M. Pantaleo (pantal@gfz-potsdam.de)
}

Received: 24 October 2013 - Published in Solid Earth Discuss.: 14 November 2013

Revised: 10 February 2014 - Accepted: 12 February 2014 - Published: 1 April 2014

\begin{abstract}
Fumarole fields related to hydrothermal processes release the heat of the underground through permeable pathways. Thermal changes, therefore, are likely to depend also on the size and permeability variation of these pathways. There may be different explanations for the observed permeability changes, such as fault control, lithology, weathering/alteration, heterogeneous sediment accumulation/erosion and physical changes of the fluids (e.g., temperature and viscosity). A common difficulty, however, in surface temperature field studies at active volcanoes is that the parameters controlling the ascending routes of fluids are poorly constrained in general. Here we analyze the crater of Stefanos, Nisyros (Greece), and highlight complexities in the spatial pattern of the fumarole field related to permeability conditions. We combine high-resolution infrared mosaics and grain-size analysis of soils, aiming to elaborate parameters controlling the appearance of the fumarole field. We find a ring-shaped thermal field located within the explosion crater, which we interpret to reflect near-surface contrasts of the soil granulometry and volcanotectonic history at depth. We develop a conceptual model of how the ring-shaped thermal field formed at the Stefanos crater and similarly at other volcanic edifices, highlighting the importance of local permeability contrast that may increase or decrease the thermal fluid flux.
\end{abstract}

\section{Introduction}

Thermal anomalies in volcanic areas may be detected before, during and long after eruptions, allowing assessment of precursors, of fluid flux and degassing intensity levels, and quantification of the volcanic heat discharge at the surface (Sekioka and Yuhara, 1974; Stevenson, 1993). Besides the magmatic/hydrothermal source itself, different factors may affect the expression and intensity of fumaroles. These may be, for instance, the stress field, the presence of faults and fractures, or the lithology (Mongillo and Wood, 1995; Dobson et al., 2003; Finizola et al., 2003; Revil et al., 2008; Schöpa et al., 2011; Peltier et al., 2012). Thermal anomalies can be detected at the surface by direct measurements and by satellite-based or hand-held infrared camera measurements (Bukumirovic et al., 1997; Harris and Maciejewski, 2000; Chiodini et al., 2007; Harris et al., 2009). These measurements alone cannot however explain which factors control the permeability complexities and the thermal expression. Therefore the question of how the thermal expression at volcanoes is affected by permeability complexities remains to be studied. Few case studies have investigated the effect of permeability on fumaroles (Mongillo and Wood, 1995; Schöpa et al., 2011; Peltier et al., 2012), highlighting the entanglement between the stress, the faults and the lithologies. Mongillo et al. (1995) showed that, at White Island, New Zealand, the tectonic structures control the site permeability at an edifice scale, whereas the lithology has a local influence on it. Schöpa et al. (2011) indicated that at Vulcano Island, Italy, the topography-induced stress field focuses the permeable pathways toward the morphological crests. At these sites both the position (e.g., inner or outer flank) and geometry (e.g., radial or concentric) are controlled by the lithology and the shallow fractures. Peltier et al. (2012) suggested that at the Yasur-Yenkahe complex, Vanuatu, the stratigraphic layering dictates the permeability setting together with faults and fractures. At a larger scale, the relation between porosity, 
permeability and fluid flow was studied at the Yellowstone caldera (Dobson et al., 2003). Here, results showed that sediments and non-welded tuffs have high permeability thanks to primary porosity. Other welded lithologies have even higher permeability because of fractures and veins, which represent the secondary porosity.

The reconnaissance of the permeability background becomes relevant to decipher the temporal and spatial variability of thermal fields as it also relates to unrest. Faults and fractures, in particular, control the permeability of the rock masses according to Darcy's cubic law (Caine et al., 1996; Faulkner et al., 2010), whereas the permeability of soils relates to the grain-size distribution as well as compaction, cementation and alteration (Shepherd, 1989; Benson et al., 1995); consequently they all accomplish convective heat flow (Hardee, 1982). Variations in volcanic and geothermal activity have been frequently observed at sites such as Vulcano Island, Italy (Bukumirovic et al., 1997; Harris and Maciejewski, 2000), at Iwodake Volcano, Japan (Matsushima et al., 2003), at the Solfatara of Pozzuoli, Italy (Chiodini et al., 2007), and at Colima, Mexico (Stevenson and Varley; 2008), but they were alternatively attributed to changes in the magmatic or hydrothermal source (Stevenson, 1993), to permeability changes due to conduit sealing by deposition or tectonic activity (Harris and Maciejewski, 2000), or a combination thereof. Examples of chemical and thermal changes were also recently documented for the 2011-2012 unrest episode at Santorini (Parks et al., 2013; Tassi et al., 2013).

In this work we test the influence of permeability by analyzing the stratigraphic and volcanotectonic setting in controlling the degassing sites at Nisyros Island. We first explore if the results from thermal mapping and soil analysis correlate, both possibly reflecting the local geology. On the one hand, we make use of a portable infrared (IR) camera, which is efficient in imaging volcanic regions at metric to sub-metric resolutions, overcoming the low spatial resolution of satellites and the cost- and time-consuming thermometerbased measurements. On the other hand we collect and sieve soil samples at the fumarole field to define soil types and related permeabilities. Finally we compare the spatial permeability contrasts with the spatial distribution of the thermal anomalies. Our testing location was the Stefanos crater on Nisyros (Fig. 1). This volcanic island has a long history of phreatic eruptions, the latest in 1871-1873 and 1887 (Marini et al., 1993), experiencing an episode of unrest in 1996-2001 (Papadopoulos et al., 1998; Chiodini et al., 2002; Sachpazi et al., 2002). The Stefanos crater is one of several phreatic craters on Nisyros, and is also the major contributor to the total heat budget of the island (Lagios et al., 2007; Ganas et al., 2010). Below we first introduce the study area, the infrared and soil analysis methods, followed by our results that allow an interpretation of how the permeability might control the appearance of thermal anomalies.
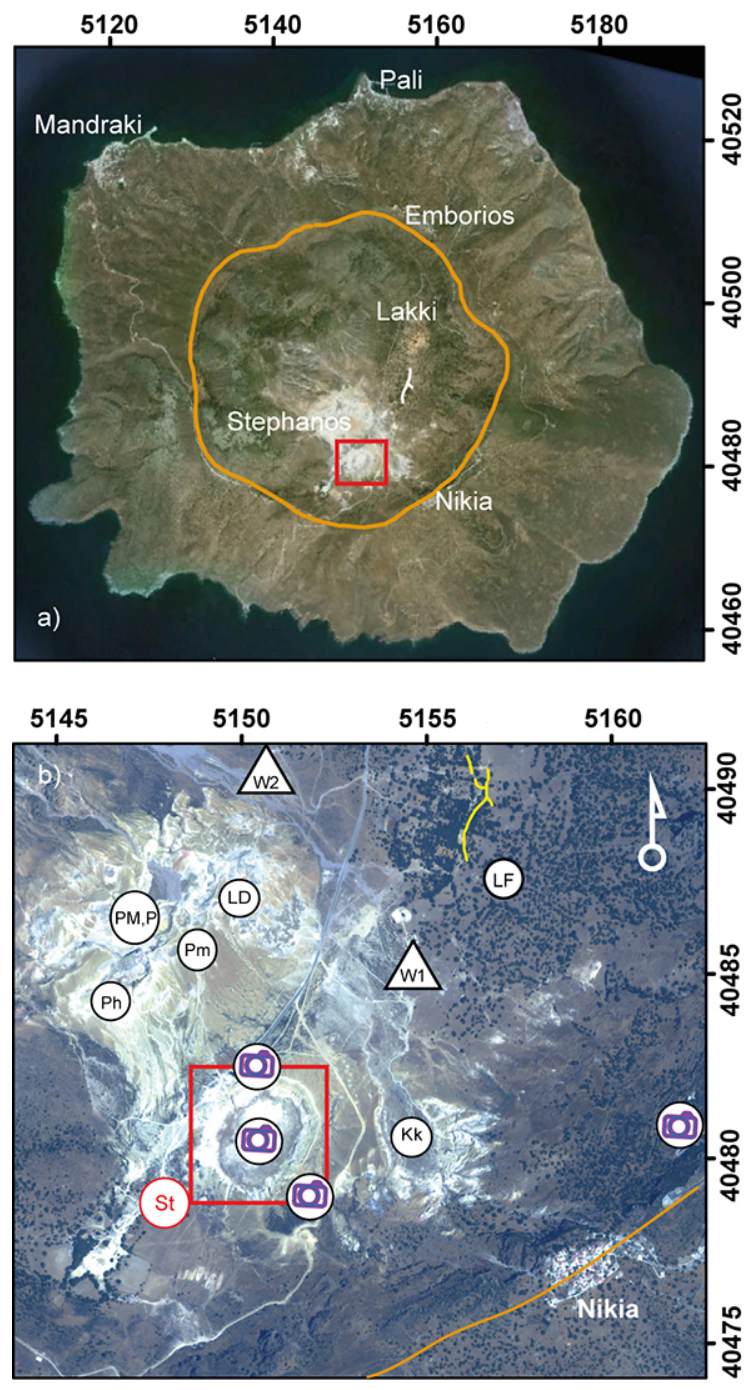

Fig. 1. (a) Nisyros Island. Coordinates are in UTM, zone 35, grid ticks are at $2 \mathrm{~km}$. The brown line marks the border of the caldera. Inside the caldera: the red square shows the position of the Stefanos crater; the white line highlights the 2001-2002 fissure at the Lakki plain. Other toponyms outside the caldera indicate the villages on the island. (b) Satellite image (WV02) showing the main volcanic features inside the caldera; grid ticks are at $500 \mathrm{~m}$. The red square indicates the Stefanos crater labeled St; other labeled sites are the Kaminakia crater (Kk), the Lofos dome (LD), the nested Polybotes Megalos and Polybotes craters (PM,P), the Polybotes Micro crater $(\mathrm{Pm})$ and the Phlegeton crater $(\mathrm{Ph}) . \mathrm{LF}$ is the fissure in the Lakki plain. The camera icons point out the position where IR and OP images were collected, inside/outside of the Stefanos crater and at the caldera border (brown line). W1 and W2 indicate the positions of two geothermal wells. 


\section{Study area}

\subsection{Geological background}

Nisyros is a volcanic island in the South Aegean active volcanic arc related to the northward subduction of the African plate below the Aegean plate. The island is sub-circular in plan view with a diameter of $\sim 7 \mathrm{~km}$ and morphologically appears like a truncated cone. The volcanic edifice developed through five distinguished stages (Marini et al., 1993; Tibaldi et al., 2008) that led to the formation of a $\sim 4 \mathrm{~km}$-wide caldera, hosting rhyodacitic domes in the west and an alluvial plain in the eastern part, respectively. Superheated geothermal fluids have triggered hydrothermal explosions forming several phreatic craters, most recently in 1887 (Marini et al., 1993). The largest of these craters is the Stefanos crater, with a diameter of $\sim 300 \mathrm{~m}$ (Fig. 1), which is in the focus of our study.

\subsection{Hydrothermal activity}

The remarkable hydrothermal activity, hot springs and fumaroles motivated site studies and the drilling of two deep wells for geothermal exploitation (Geotermica Italiana 1983, 1984; Marini et al., 1993). These gave a direct view into the hydrogeological and hydrothermal system. Geochemical analyses (Chiodini, 1993; Lagios et al., 2007) helped to characterize the system, and the fumaroles on Nisyros were investigated in detail (Chiodini, 1993; Chiodini et al., 2002; Teschner et al., 2007).

The hydrogeological system of the caldera consists of two separate permeable zones, as identified by the drilling of two geothermal wells (Geotermica Italiana, 1983, 1984; W1 and W2 in Fig. 1b). One permeable zone is found at a depth $>1000 \mathrm{~m}$, the other is located at a depth of $\sim 200 \mathrm{~m}$. Both the permeable zones are deeper in the eastern part of the caldera. This vertical offset relates to a graben-like structure of the caldera basement (Caliro et al., 2005). The deep permeable zone is developed within the intrusive dioritic basement, but ends at the overlying carbonate and volcanic sequence. This permeability contrast is attributed to diverse fracture density between the lithologies (Ambrosio et al., 2010). The deep permeable zone has a temperature range of $300-350^{\circ} \mathrm{C}$ and the heat is provided by magmatic fluids (Caliro et al., 2005; Lagios et al., 2007). The deep permeable zone provides vapor to the shallow permeable zone, which has a temperature range of $150-260^{\circ} \mathrm{C}$ (Chiodini et al., 2002, Lagios et al., 2007). Finally, Lagios et al. (2007) proposed that a third still shallower reservoir exists and is fed by condensates.

At the surface, fumaroles occur mainly at phreatic craters such as at Stefanos, Phlegethon, Polybotes Micros (St, Ph, $\mathrm{Pm}$ in Fig. 1b), and at the eastern base of the Lofos dome (LD in Fig. 1b). Temperature measurements at the phreatic craters have been conducted for decades, recording fumarole outlet temperatures of mostly $96-100^{\circ} \mathrm{C}$ (Chiodini et al.,
2002; Teschner et al., 2007). Smaller fumaroles occur along the flanks and on top of the Lofos dome and at the Kaminakia crater flank (LD, Kk in Fig. 1b). Some degassing vents occur also along the southern and western internal flank of the caldera following the NE-SW trends, which represents one of the main fault strikes recognized by Caliro et al. (2005), Lagios et al. (2005) and Tibaldi et al. (2008).

A 100-year period of quiescence ended with the 19962001 unrest episode. During this period, field observations report increased fumarole activity in 1997 (Vougioukalakis and Fytikas, 2005). Other phenomena attributed to the unrest include the progressive opening of a fissure in the Lakki plain since 2001 (Vougioukalakis and Fytikas, 2005; Fig. 1). Monitoring of the fumaroles at Nisyros since 2003 (Teschner et al., 2007) indicates that the outlet temperature only fluctuates by a few degrees due to variations in meteorological conditions. Satellite TIR data from 2000-2005 indicate that the Stefanos crater hosts a high temperature anomaly and contributes the most to the total heat flux budget of the caldera (Lagios et al., 2007; Ganas et al., 2010). In the same period, gravity surveys reveal short-term changes (Gottsmann et al., 2005) occasionally associated with height changes, inferred to reflect instabilities of the hydrothermal system (Gottsmann et al., 2007). However, these variations do not appear in the temperature data of Teschner et al. (2007). More recent ground-based InSAR measurements (2010) could not detect a significant displacement signal, implying a general decrease in activity and suggesting that the hydrothermal system is close to rest conditions (Pantaleo, 2014).

While the previous studies suggest that hydrothermal activity at depth and at the surface are related, a direct study on how the fumarole field depends on the near-surface permeability has not been elaborated. In this paper, we investigate the relationship between the thermal activity and the permeability contrast. Thermal activity was recorded by means of infrared measurements, whereas the permeability was analyzed indirectly by granulometry. A better understanding of the thermal field allows important implications in the framework of hazard assessments for the hydrothermal activity at the site.

\section{Method}

\subsection{Infrared (IR) survey}

A forward-looking infrared camera (FLIR P620) was used to collect images of the $200 \times 300 \mathrm{~m}$-large Stefanos crater in normal and panorama mode (Fig. 1). The camera operates at $7.5-13 \mu \mathrm{m}$ bandwidth. The image size is $640 \times 480$ pixels and the resolution is 0.33 or $0.65 \mathrm{mrad}$ (different lenses were used at different monitoring distances). The dimension of the pixel size is given by the resolution (mrad) times the distance of the target $(D)$. The camera also hosts a digital optical sensor, allowing joint acquisitions of target regions. In 

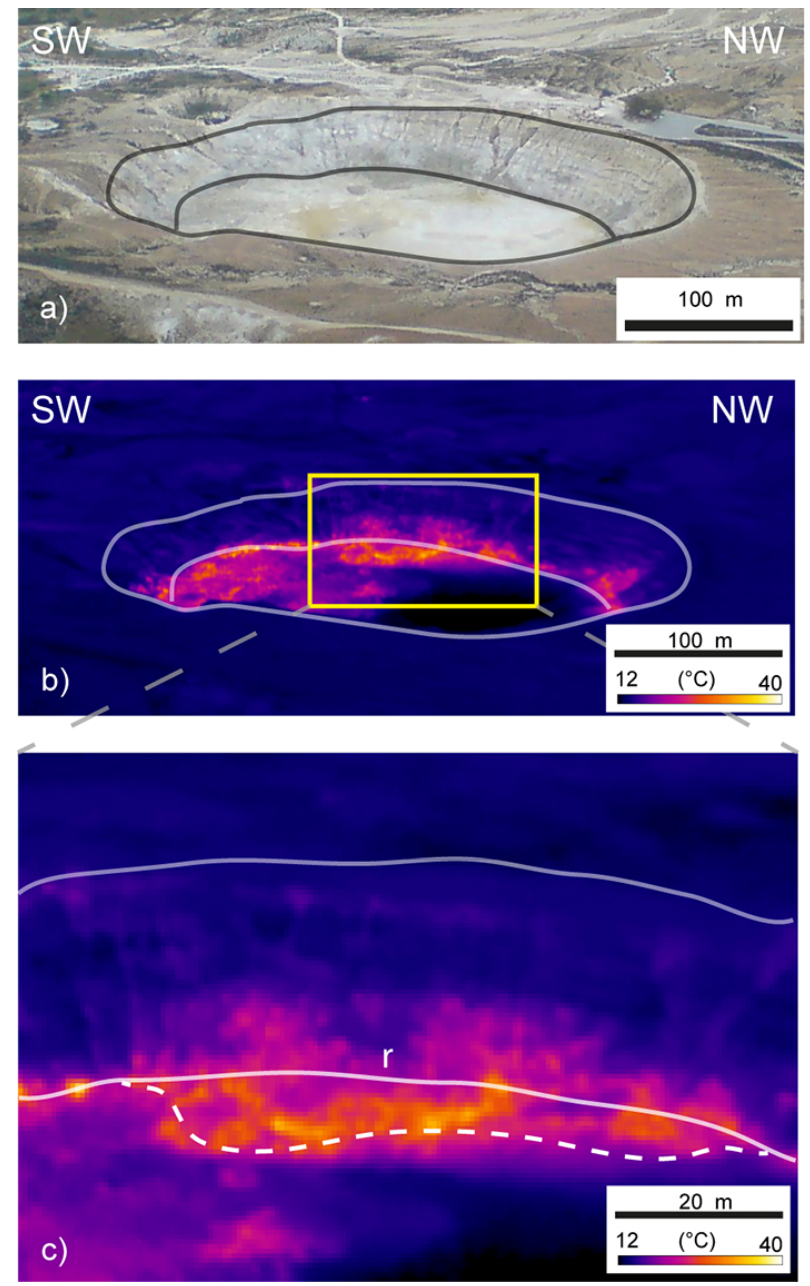

Fig. 2. (a, b) OP and IR images collected from long distance (caldera rim, Fig. 1b). Solid lines mark the upper and lower crater rim. Both the OP and IR images display part of the crater floor and the east-facing flank; the IR images show thermal anomalies along the bottom rim and a weaker anomaly toward the center of the crater but also propagating to the south. The yellow rectangle in (b) defines the area shown by the close-up in (c). (c) Magnification of the wide thermal anomaly ( $r$, dashed line) on the western side of the crater. The coarse spatial resolution $(\sim 0.8 \mathrm{~m})$ causes the smoothed appearance of the temperatures.

total we recorded $>200$ images to ensure ideal clear viewing conditions and the feasibility of image stitching, in order to investigate the thermal field at different scales (Figs. 2, 3 and 4). On average 4-10 images were necessary to create mosaic panoramas (Fig. 3) for both infrared and optical images, and $\sim 30$ images to create the synoptic IR map of high spatial resolution (Fig. 4).

A data set of images was collected on the 7 April 2010 during a single day. During daytime the images from the caldera rim were collected at 08:30 (local time), and the images from outside and inside the crater were collected between 12:30 and 14:00 (local time). During nighttime the images were
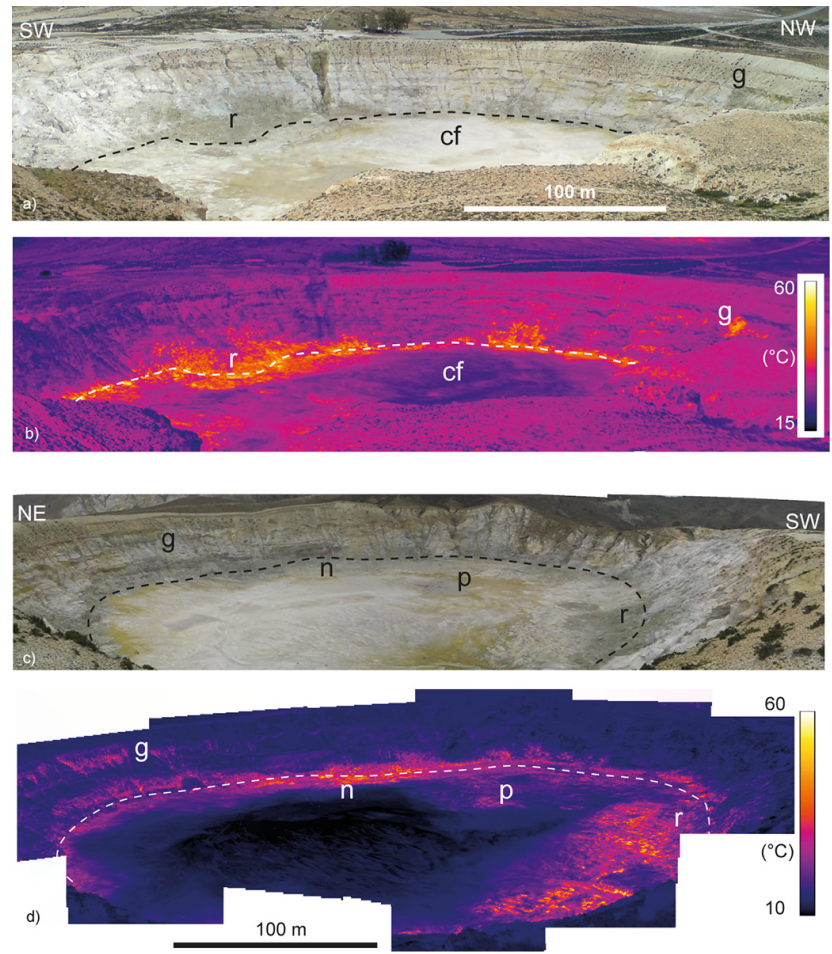

Fig. 3. (a, b) OP and IR daytime panorama viewing westward; the dashed line marks the crater's bottom rim. (b) The thermal anomaly is visible at the break in slope of the flank and is wider in correspondence to the mound (r). The crater floor (cf) and the flank are generally cold; the lateral thermal gradient (from SW to NW) on the flank appears because of the insolation. The thermal anomaly along the flank $(\mathrm{g})$ is volcanic and is stronger than the insolated areas. The insolation and the fine spatial resolution allow the IR data to display morphological features (e.g., horizontal layering, gullies). Temperature values are saturated at 15 and $60^{\circ} \mathrm{C}$ to optimize the view. (c, d) OP and IR nighttime panorama facing southeastward; the dashed line marks the crater bottom rim. (d) The thermal anomaly clearly shows its ring-shaped pattern at the break in slope of the flank; at the eastern (n) and western (r) sides the anomaly appears to be wider. Another anomaly (p) appears close to the center in the southern direction and represents the mud pits. Also visible is the thermal anomaly (g) along the flank, as observed in (Fig. a, b). Temperature values are saturated at 10 and $60^{\circ} \mathrm{C}$ to optimize the view. (a) and (c) also show the sites with high sulfur content (yellowish).

collected from outside and inside the crater between 22:15 and 23:00 LT. Images from long distances were collected from the caldera rim close to Nikia (Fig. 1); here we used a telezoom to obtain a spatial resolution of $\sim 0.8 \mathrm{~m}$ (Fig. 2). Images from shorter distances were recorded in panorama mode from two opposite vantage points along the crater rim. One subset was recorded from a position $\sim 200 \mathrm{~m}$ southeast of the crater (Fig. 1b) showing the center of the crater and the east-facing Stefanos crater flank (Fig. 3a and b). The other subset viewed the crater from $\sim 100 \mathrm{~m}$ northwest of the Stefanos crater rim (Fig. 1b) showing the bottom of the crater 
and its southeastern flank (Fig. 3c and d). For these subsets, the pixel dimension ranged between 0.05 and $0.15 \mathrm{~m}$. Differences exist between the panoramas because the vantage points had different distances leading to a different field of view and incidence angles. A $360^{\circ}$ panorama was recorded at the bottom of the crater (Fig. 1b), and these images were used to generate an IR mosaic of the entire crater (Fig. 4) and to detail small-scale features on the crater floor.

The IR images display temperatures on a color-coded scale, and these temperatures are considered apparent. That is, the temperature value represents the thermal energy distribution integrated over the pixel footprint (Dozier, 1981); accordingly,

$T_{\mathrm{obj}}=A_{\mathrm{v}} \times T_{\mathrm{v}}+\left(1-A_{\mathrm{v}}\right) \times T_{\mathrm{b}}$,

where $\left(T_{\mathrm{obj}}\right)$ is the pixel temperature, and $A_{\mathrm{v}}$ and $\left(1-A_{\mathrm{v}}\right)$ are the vent area and the vent-free area within the unitary pixel, respectively; $T_{\mathrm{v}}$ and $T_{\mathrm{b}}$ are the temperature $\left({ }^{\circ} \mathrm{C}\right)$ of the vent and of the background, vent-free area, respectively. Otherwise $T_{\mathrm{obj}}$ depends on parameters like the target-to-sensor distance $(D)$, the emissivity of the target, and the transmittance of the atmosphere as a function of atmospheric temperature $\left(T_{\mathrm{atm}}\right)$ and relative humidity $(\mathrm{RH})$. Finally, the accuracy of the measurements depends on the orientation of the field of view, which should be as parallel as possible to the target (Ball and Pinkerton, 2006).

For each data set acquired in panorama mode, the images were sampled in fast sequence steering the IR camera and allowing a sufficient overlap between consecutive pictures. Because the distance was almost constant for each of the shooting positions and the time required between each acquisition is a few seconds only, the parameters $D, T_{\text {atm }}$ and RH were assumed constants. Values of $T_{\text {atm }}$ and $\mathrm{RH}$ are assumed to be suitable to site conditions in the range of 10 $20^{\circ} \mathrm{C}$ and $50 \%$, respectively. Also, $\varepsilon$ is assumed to be constant and equal to 0.93 according to the literature (Lagios et al., 2007). All these assumptions were valid also for the other IR images collected as independent snapshots. We did not consider a pixel-by-pixel correction approach. Also, geometric complexities arising from the different viewing field and topography were not corrected for.

We processed the raw images by FLIR ThermaCAM software. The results are displayed (Figs. 2-4) with temperature scales saturated and clipped at the $10-60^{\circ} \mathrm{C}$ interval for the night panorama, and at $15-60^{\circ} \mathrm{C}$ and $15-90^{\circ} \mathrm{C}$ for day panoramas, respectively, to enhance the thermal patterns. The stitching of infrared and digital images is finally executed using a combined perspective-cylindrical merging tool as embedded in common image software (Photoshop). The images taken from within the crater floor were also used to generate a crater-wide mosaic that is subsequently georeferenced in map view (Fig. 4) with GIS software (ArcGIS 9.3 by ESRI). This necessitates the application of a matching proce-
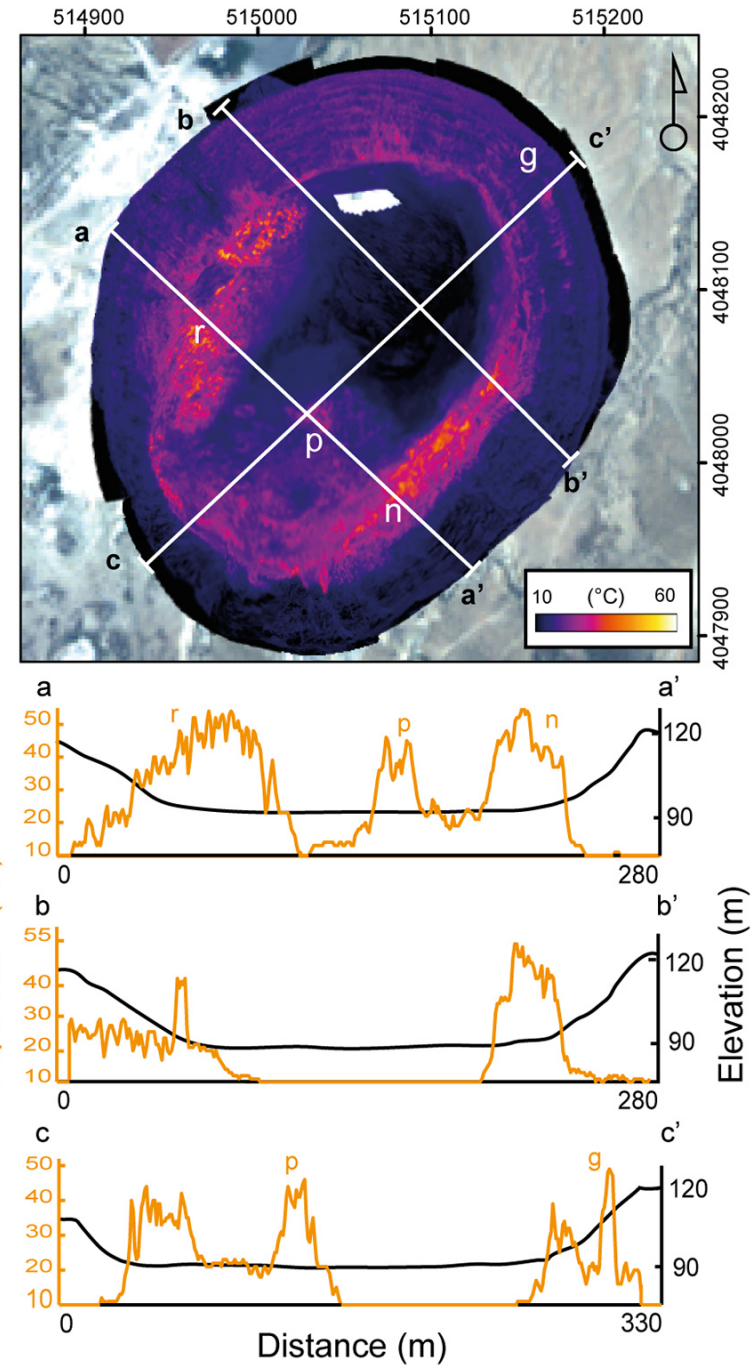

Fig. 4. (Above) Georeferenced IR mosaic showing the full extent of the ring-shaped thermal field along the bottom crater rim. Grid ticks are at $100 \mathrm{~m}$. This map better highlights the NW-SE trending of the wider anomalies including the mounds (r, n) as well as the isolated position of the boiling ponds (p) and of the anomaly along the northern flank $(\mathrm{g})$. Temperature values are saturated at 10 and $60{ }^{\circ} \mathrm{C}$ to optimize the view. Three orthogonal traces $\left(a-a^{\prime}, b-b^{\prime}\right.$, $\left.c-c^{\prime}\right)$ are shown intersecting those features. (Below) Temperaturetopography profiles $\left(a-a^{\prime}, b-b^{\prime}, c-c^{\prime}\right)$; the distances along the trace and the topographic height ( $x-y$ axes are not scaled) are in black; the temperature axis and the values are in orange. These profiles highlight the fact that thermal anomalies occur mostly at breaks in the slope.

dure of ground control points recognized in both the satellite image (WorldView02, visible bands) and the IR mosaic.

A second field survey on 17 January 2013 allowed for the collection and verification of the IR images collected in 2010. The survey followed a similar procedure, except that the images were taken from the northern and southern borders of 

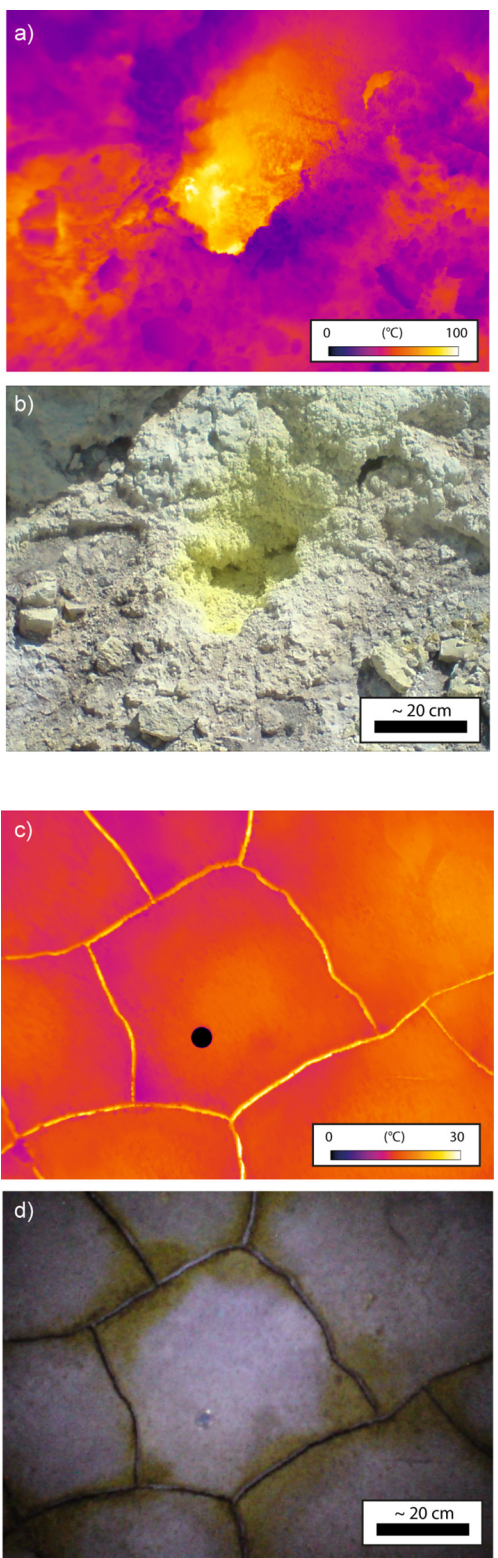

Fig. 5. (a, b) IR and OP close-ups of a fumarole on the western mound. The IR image shows that the temperature at the vent reaches $100^{\circ} \mathrm{C}$, according to direct measurements. This is possible as the pixel size is sub-mm. It also shows that temperature rapidly decreases sideways. The same can be deduced by the OP, where solid sulfur exists close to the degassing vent. (c, d) IR and OP close-up of the dessication polygon. The IR image shows the plate as cool, whereas the bounding fracture is $\sim 5^{\circ} \mathrm{C}$ warmer. The black circle is a 1 Euro coin for scale; it appears cooler because it has an emissivity different from the emissivity of the soil. The OP image shows the sulfur crystallization close to the fracture.

the crater. The crater floor could not be imaged because it was partially flooded by recent rainfall.
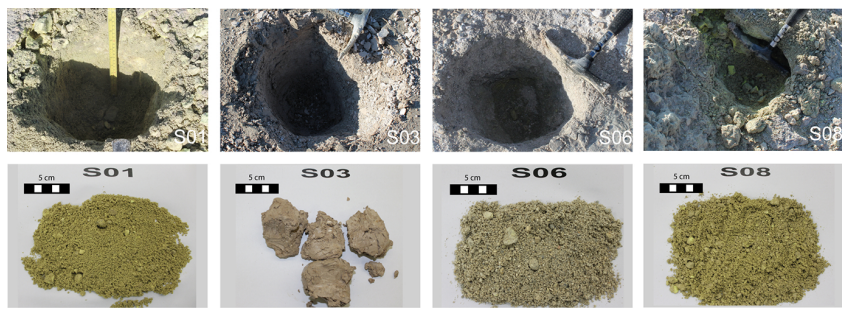

Fig. 6. (upper row) Digital pictures of the pits where soil samples were collected and (lower row) corresponding material. The difference between granular and cohesive types can be distinguished visually. S01 is loose and shows few clasts $\geq 1 \mathrm{~cm}$ dispersed in an $\sim$ uniform fine sand matrix. S03 occurs in blocks of cohesive material and no particle can be distinguished. S06 is loose and shows few clasts $\geq 1 \mathrm{~cm}$, but the matrix is graded. S08 has few clasts $\geq 1 \mathrm{~cm}$ and appears graded. S01 and S06 also have sulfur grains, as indicated by the yellowish color.

\subsection{Soil analysis}

Soil samples (12) were collected (Fig. 6) during our 2013 campaign on 18 January. Sampling locations were chosen at the crater floor mainly along an E-W profile (Fig. 7) crossing fumarole-bearing and fumarole-free areas. Two samples were collected along the eastern flank and two more samples in the southern and northern sectors, corresponding to sites of anomalous and normal temperature, respectively (Fig. 7). The sampling sites were selected according to the need to (i) represent the different thermal conditions and expressions (fumarole, diffusively heated ground, mud pools, boiling runoff) highlighted by the 2010 infrared survey, (ii) to have a sampling dense enough for spatial comparison to thermal data, and (iii) to limit the total weight. The E-W profile allowed us to intersect the thermal anomalies at the crater border, the center, and the interposed cool areas. A N-S profile instead would have neglected the large thermal anomalies observed at the western and eastern flank bases. Moreover, the N-S elongation of the flooded area would have caused a large gap in the spacing of soil samples. The representativeness of the bulk grain-size distribution was ensured by collecting 1-2 kg of a sample, depending on its cohesive or granular aspect defined in the field.

Each sample was collected at a depth up to $20 \mathrm{~cm}$ below the surface. We ensured that the sample corresponded to a single soil type. We dug down to $50 \mathrm{~cm}$ in an attempt to check for a possible vertical gradient in temperature. Each soil sample has been characterized by grain-size analysis in the laboratory. Samples were oven dried at $70^{\circ} \mathrm{C}$ to avoid melting of sulphur crystals before weighing. Samples were wet sieved (ASTM-D6913-04, 2009) to discern the relative percentage of granular fractions, particles with diameter $(d)$ larger than $0.064 \mathrm{~mm}$, and cohesive fraction, particles with $d$ smaller than $0.064 \mathrm{~mm}$. The cohesive component is washed away by running water filtered by sieves, while the granular 

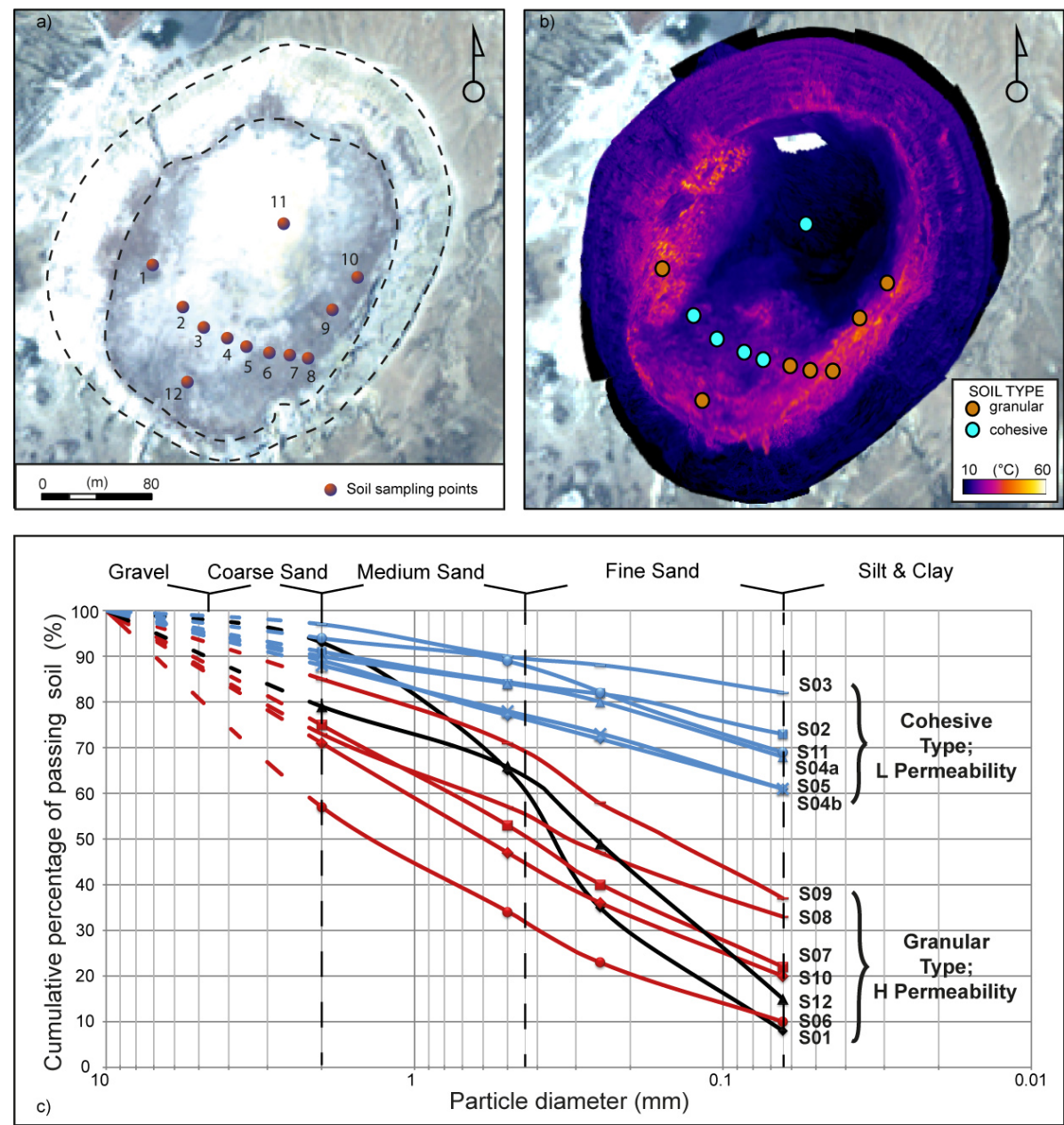

Fig. 7. (a) Optical satellite image (WV02) of the Stefanos crater: the numbered dots mark the sites where soil was sampled. (b) Georeferenced IR mosaic overlapping the satellite images; it shows the coupling of soil types with the thermal field. (c) Semi-logarithmic plot of grain-size curve. The vertical axis indicates the cumulative percentage (by weight) of material passing through the sieves; the lower horizontal axis indicates the mesh diameter of the sieves. The upper horizontal axis indicates the fraction names and intervals according to international standards. The blue lines are the grain-size curves of cohesive type soils, which have low (L) permeability. The red and black lines indicate the grain-size curves of granular type soils, which have high $(\mathrm{H})$ permeability. The red curves are for sorted samples, the black for more uniform samples. Blue, red and black lines are solid within the measured intervals and dashed where uncertainty arises by assuming a maximum diameter of $10 \mathrm{~mm}$ and interpolating the curve (see text).

material is kept on them. Finally, the soil trapped by each sieve is dried and weighed again.

We used four sieves that allowed us to separate gravel and coarse sand fraction $(d>2.0)$, medium sand fraction $(2.0<d<0.5)$, fine sand fraction $(0.5<d<0.064)$, and silt and clay fraction $(d<0.064)$. The maximum $d$ for each sample was noted visually; few clasts exceeded $10 \mathrm{~mm}$. We did not perform a settling analysis to compute the relative percentage of silt and clay.

Following geotechnical practice, the results are presented as distribution curves in a semi-logarithmic plot (Fig. 7); the vertical axis indicates the cumulated percentage (by weight) of soil passing through the sieve whose mesh size is labeled on the horizontal axis. In this plot, we adopt $d=10 \mathrm{~mm}$ as the maximum value and assume that all the material is smaller, so the grain-size curve results are interpolated from $d=2 \mathrm{~mm}$ to $d=10 \mathrm{~mm}$ (dashed curves in Fig. 7).

Although our main analysis and result is based on the granulometry, we also estimate the permeability $(k)$ of our samples by applying the empirical formula by Alyamani et al. (1993). Permeability is accordingly based on the knowledge of $d_{10}, d_{50}$ (particle diameter values at the 10 and 50 percentage of the grain-size curve, respectively) and $I_{0}$ (the intercept of the line formed by $d_{50}$ and $d_{10}$ with the diameter axis). The parameters $d_{50}$ and $d_{10}$ were extracted from linear interpolation of the grain-size curves. Both particle diameter values could be directly obtained from samples S01 and S06. For the other samples, however, the measured grain-size 
curve does not intercept the $10 \%$ of passing soil. To provide a first-order estimate for these other samples, we arbitrarily constrain $d_{1}=0.002 \mathrm{~mm}$, which means that samples have $1 \%$ of clay content in the cumulate curve. Furthermore, we constrain $I_{0}=0.001 \mathrm{~mm}$. The aforementioned constraint cannot be applied to the cohesive samples, because they are mainly silt-clay material and so, given our grain-size curves, any prediction of $d_{50}, d_{10}$ and $\mathrm{I}_{0}$ would be unrealistic. For the cohesive samples, we hence refer to the related literature (Bowles, 1988).

\section{Results}

\subsection{Far field view of large-scale thermal architecture}

The IR images collected from the caldera rim, about 1000$1200 \mathrm{~m}$ away from the Stefanos crater (Fig. 1), have a coarse resolution with pixel size of about $0.60-0.80 \mathrm{~m}$. They show the western flank of the crater and part of the bottom, the remaining parts are not imaged because of the topographyrelated shadowing effect (Fig. 2a and b). The upper rim of the crater does not express any thermal anomaly, whilst the bottom rim of the crater does; the temperature field is shown by a ring not perfectly concentric bordering the crater floor (Fig. 2b). The temperature distribution is smoothed and homogenized because of the coarse resolution, therefore single or grouped vents cannot be recognized (Fig. 2c). On the western and southern sides, more elevated temperatures and wider thermal fields can be observed. At the southern side the apparent temperature $(T)$ is in the range $22-30^{\circ} \mathrm{C}$ and rises to $30-40{ }^{\circ} \mathrm{C}$ westward ( $\mathrm{r}$ in Fig. $2 \mathrm{c}$ ) before decreasing to $24-30^{\circ} \mathrm{C}$ northward. The background cool temperature inside the crater is $\leq 18^{\circ} \mathrm{C}$. Further clustered anomalies are observed toward the center of the crater; these display an apparent $T$ of $20-25^{\circ} \mathrm{C}$ and mark the transition between a relatively warm southern sector and relatively cold northern sector.

\subsection{Close field view of medium-scale structures}

The mosaics produced with images collected close to the Stefanos crater have a high resolution of about 0.05 and $0.15 \mathrm{~m}$ in pixel size (Fig. 3). These mosaics show that the thermal anomalies are distributed in a roughly circular-shaped pattern at the margin of the crater floor (Fig. $3 b$ and d). The anomalies are wider along the west, through the south, to the eastern side and narrower at the opposite side. Hotter spots corresponding to clustered vents are now distinguished as sparsely distributed within the geothermal field, showing apparent temperatures of $T \geq 60^{\circ} \mathrm{C}$. The western side hosts a mound of material ( $\mathrm{r}$ in Fig. 3a and b), 2-3 m high, $\leq 10 \mathrm{~m}$ wide and $\sim 50 \mathrm{~m}$ long, covered by a hard crust dotted by centimeter-size vents; around the mound the crater floor is diffusively heated at apparent $T \sim 40^{\circ} \mathrm{C}$. The southern side has a rough surface with an extensively developed hard crust covered by pebbles/boulders fallen from the adjacent flank (Fig. 3c and d). Here there are few vents and the heat is pervasively distributed across the surface, so the apparent $T$ is $\sim 30^{\circ} \mathrm{C}$. The eastern side is flat except for a mound ( $\mathrm{n}$ in Fig. $3 \mathrm{c}$ and d), $0.5-1 \mathrm{~m}$ high, $2-3 \mathrm{~m}$ wide and $\sim 30 \mathrm{~m}$ long, hosting vents; the base of this flank also hosts surficial boiling runoff and small boiling ponds (up to tens of $\mathrm{cm}$ in size). The apparent $T$ of the thermal anomaly at this side is $\geq 40^{\circ} \mathrm{C}$. Toward the center of the crater embedded in the cooler terrain, we identify thermal anomalies - apparent $T \sim 30^{\circ} \mathrm{C}$ - corresponding to sub-metric to metric wide boiling ponds fed by meteoric water and superficial runoff. Another localized anomaly is isolated along the northeastern flank on the slope ( $\mathrm{g}$ in Fig. 3b and d); its apparent temperature is $25-30^{\circ} \mathrm{C}$ or higher, depending on the viewing geometry. Both optical panoramas show the aforementioned morphologies (mounds $\mathrm{r}, \mathrm{n}$ and ponds) as well as the sites with high sulfur content (yellowish) at the crater floor and along the flanks (Fig. 3a and c), which are not detectable in the infrared panoramas.

Temperature values from IR images are generally lower than inferred from pointwise measurements because the vent usually occupies a small part of the pixel and contributes proportionally to the pixel thermal budget. Only the IR close-up of the fumarole clearly displays $T$ values of $\sim 100^{\circ} \mathrm{C}$.

\subsection{Close-up of small-scale structure}

Using the images collected within the crater, we can further explore particular features that are not revealed from larger distances. Indeed, the resolution approach millimeters scale when standing above the targets. The IR measurements taken directly above the fumaroles show that the vent temperature decreases rapidly from $\sim 100{ }^{\circ} \mathrm{C}$ to $30-40{ }^{\circ} \mathrm{C}$ sideways (Fig. 5). Such a vent temperature is in agreement with the temperature measured inside the vent by the K-type thermocouple during our survey, and confirms findings by previous authors (Chiodini et al., 2002; Teschner et al., 2007). Similarly, the close-up of the mud pits shows the temperature decreasing rapidly from $\sim 60^{\circ} \mathrm{C}$ at the deep-seated boiling surface to almost to $20^{\circ} \mathrm{C}$ at the surface. The ground surrounding the ponds is cold and a network of cracks separate desiccation polygons (Fig. 5), usually $10-20 \mathrm{~cm}$ a side, whose surfaces have sulfur films developing from the crack inside the polygon. The cracks are warmer than the plate and we also observed the soil temperature increasing $\sim 5-10^{\circ} \mathrm{C}$ a few centimeters below the crust. Such a pattern resembles on a small scale the one observed at the crater scale.

\subsection{Mosaic of large- to small-scale structure}

The thermal features are visualized in the georeferenced IR mosaic giving a synoptic view of the crater (Fig. 4). A total of $>30$ images have been stitched and $\geq 5$ ground control points have been selected to reference each image. The 
Table 1. Permeability values for granular soil samples computed according to Alyamani et al. (1993).

\begin{tabular}{llllllll}
\hline Sample & S01 & S06 & S07 & S08 & S09 & S10 & S12 \\
\hline Permeability $\left(\mathrm{ms}^{-1}\right)$ & $1.79 \mathrm{E}-06$ & $2.17 \mathrm{E}-05$ & $1.94 \mathrm{E}-06$ & $1.12 \mathrm{E}-06$ & $3.82 \mathrm{E}-07$ & $4.56 \mathrm{E}-06$ & $6.50 \mathrm{E}-07$ \\
\hline
\end{tabular}

IR map shows most of the crater except for a small patch in the cold region, which was not covered by any image. The geothermal field, expressed by the ring-shaped thermal zone, is located along the border of the crater floor. The ring is not perfectly symmetric, but appears wider on the eastern and western sides ( $\mathrm{n}$ and $\mathrm{r}$ in Fig. 4). Here, the two opposing flanks are expressed by the highest temperatures recorded. This geometric symmetry reveals alignments of elevated thermal fields trending SW-NE. We note that the same SW-NE trend is already identified by the long axis of the ellipticity of the crater and by one of the main structural trends seen elsewhere on the island (Caliro et al., 2005; Tibaldi et al., 2008). The mosaic also shows the thermal anomaly associated with the boiling ponds, in contrast with the cold zone close to the crater center and the thermal anomaly along the NE flank ( $\mathrm{p}$ and $\mathrm{g}$ in Fig. 4). The spatial analysis reveals that the extent of the thermally anomalous area along the western flank is $\sim 2400 \mathrm{~m}^{2}$, and on the opposite flank it is $\sim 2700 \mathrm{~m}^{2}$, whereas the anomalies at the southern and northern sites cover $\sim 500 \mathrm{~m}^{2}$ each. The anomaly at the center is smaller, being only $\sim 70 \mathrm{~m}^{2}$. The overall heated $\left(>30^{\circ} \mathrm{C}\right.$ ) area is therefore $\sim 6200 \mathrm{~m}^{2}$ and corresponds to $17 \%$ of the $\sim 35300 \mathrm{~m}^{2}$-wide crater floor. We selected $30^{\circ} \mathrm{C}$ as the threshold because it effectively separates the geothermal effect from effects of insolation. We show three cross sections to highlight the spatial relationship between the thermal anomalies and the topography (Fig. 4). All the sections show that temperatures augment toward the crater floor and that the increase is gradual or sharp, depending on whether the ground is insolated or shadowed, respectively. For example, the profile $b-b^{\prime}$ shows temperature fluctuations along the western flank that reflect the stratigraphic layering. The highest temperatures are reached at the breaks in slope, but the extents are different, as $a-a^{\prime}$ crosses the wide anomalies $(\mathrm{r}, \mathrm{n})$, whereas $b-b^{\prime}$ and $c-c^{\prime}$ do not. The temperatures have a tendency to diminish toward the crater center and to flatten at $10^{\circ} \mathrm{C}$ (clipped value imposed by our elaboration) in the cold areas; the only exceptions are the temperature peaks in correspondence to the boiling ponds (p). Profile $c-c^{\prime}$ also shows the thermal anomaly (g) that occurs along the flank and reaches values comparable to the anomalies at the flank base.

\subsection{Soil analysis}

We present the results from the soil analysis in the form of a semi-logarithmic grain-size curve and in an ArcGIS framework on the IR map to provide a combined view of temperature-grain-size distributions (Fig. 7). The grain-size plot shows two main groups: the cohesive type, which has $\geq 60 \%$ of cohesive fraction, and the granular type, which has $\leq 40 \%$ of cohesive fraction (Fig. 7). Both soil types are generally well graded when considering the sand fraction, with the exception of S01 and S12, which have a dominant medium and fine sand fraction. In a first-order approximation, we describe the granular type as medium-to-fine sand and the cohesive type as a silt-clay. Spatially we observe that the sample S01 (Fig. 6) collected at the base of the western mound has $93 \%$ granular content, with cohesive material being almost absent. The sample S12 collected at the southern border and below a hard crust has $85 \%$ granular content, again with a very low cohesive fraction. At the eastern flank, the samples S07, S08 (Fig. 6), S09 and S10 are granular, with percentages ranging between 64 and 80 . The samples S04 and S05 are collected as close as possible to the ponds, just a few meters, but out of the area temporarily flooded by the rain. They have granular content below $40 \%$ and significant cohesive content of about $60-70 \%$. A similar value is found in a deeper sample at the same location (S04 at $50 \mathrm{~cm}$ ), collected because the IR data showed a $\sim 35^{\circ} \mathrm{C}$ temperature increase, thus suggesting a reduction in the vertical efficiency in heat transfer. The samples S02 and S03 (Fig. 6) collected between the western flank and the mud pools have cohesive fractions ranging between 70 and $80 \%$. The sample S06 (Fig. 6) collected between the eastern flank and the mud pools is $\sim 90 \%$ granular. The soil sample S11, at the north of the mud pools where there is no thermal anomaly, has only $\sim 68 \%$ of cohesive particles.

Granular soils have higher permeability values than cohesive soils, because granular soils allow higher effective porosity (Graton et al., 1935; Shepherd 1989). The empirical formulation used to calculate the permeability of our granular samples indicates that permeability values range between $10^{-5}-10^{-7} \mathrm{~ms}^{-1}$, with sample locations S06 and S09 being the most and least permeable, respectively (Table 1). The permeability value of the cohesive soils taken from the literature corresponds to $k \sim 10^{-11} \mathrm{~ms}^{-1}$ (Bowles, 1988).

\subsection{Comparison of IR and soil analysis}

Our results show that the locations of thermal anomalies match with the locations of granular soils. Lower temperatures match with the locations of more cohesive soils (Fig. 7). We notice that S06 diverges from the general behavior by having a high granular fraction but being located in a relatively cold area. This particular sample location was close to 
the flooded area, associated with a possible cooling effect. We also note an apparent correlation between changes in the granular fraction with the spatial thermal gradient. Looking at the granular content along the E-W profile (S01-S08), we note that it decreases by over $60 \%$ from S01 to S02, which are $\sim 40 \mathrm{~m}$ apart. A further $10 \%$ decrease is found from $\mathrm{S} 02$ to S03, and a $10 \%$ increase from S03 to S06; these locations are $\sim 20 \mathrm{~m}$ apart. Higher rates (20-30\% each $20 \mathrm{~m}$ ) occur between S06-S07-S08. Similarly we observe strong horizontal thermal gradients from S01 to S02 and from S06 to S07 (30$40^{\circ} \mathrm{C}$ ), whilst from S02 to S06, the gradient is $\sim 15^{\circ} \mathrm{C}$. The granular content along the $\mathrm{N}-\mathrm{S}$ profile $(\mathrm{S} 08-\mathrm{S} 10)$ appears more stable, as indicated by the horizontal thermal gradient too.

\section{Discussion}

This work demonstrates a relationship between the thermal anomaly and the grain-size distribution of the soil present in the largest explosive crater on Nisyros Island. The Stefanos crater is known for the significance of the geothermal activity, the fluid emissions and the short-term episodes of uplift and gravity changes. We analyzed the thermal field by means of a multi-scale infrared study, retrieving spatial resolutions (pixel size) of 0.05 to $0.8 \mathrm{~m}$. Results show a complex, accurate, high-temperature field bordering the center of the crater floor that is expressed more strongly on the western and eastern sides. Here the temperature is not only higher but the thermal field is also wider. To test this temperature distribution in more detail, we collected soil samples and identified the granulometry. We find a first-order correlation between the grain-size distribution of the soil, which we consider as a proxy for soil permeability, and the temperature distribution.

Understanding the dynamics of the degassing close to the surface at Nisyros is of relevance, as the volcano is currently ranked in the "Very High Threat" class (Kinvig et al., 2010), considering the vulnerability of the population $(\sim 1000)$ and seasonal tourists $(\sim 60000)$. The Stefanos crater was chosen for our study because of a recent increase in fumarole activity and outflow of melted sulfur and hot mud (Papadopoulos et al., 1998; Chiodini et al., 2002; Sachpazi et al., 2002; Vougioukalakis and Fytikas, 2005; Lagios et al., 2007), as well as its strong thermal signature in comparison to other phreatic craters (Lagios et al., 2007; Ganas et al., 2010). Moreover, our results may have implications relevant for other sites. The Stefanos crater is a rather typical explosive phreatic crater with a morphometry similar to those found on other volcanoes. The Stefanos crater also displays a ring-shaped thermal pattern of fumaroles similarly observed at other volcanic craters, such as at Vulcano (Bukumirovic et al., 1997), Satsuma-Iwojima (Shinohara et al., 2002), Colima (Varley and Taran, 2003), and Kudrayavy (Yudovskaya et al., 2008). Vulcano and Kudrayavy in particular could be excellent case studies to validate or challenge our findings because their summit craters are collectors of sediments and because they are safely accessible. At the other active volcanoes, direct soil sampling, however, is dangerous, making similar studies difficult.

\subsection{Limitations}

We surveyed the site during a single day in 2010 and for 2 days in 2013, in both cases collecting images at day and night time. During this interval Nisyros Island was quiescent and we decided to test whether some long-term changes might have occurred in the hydrothermal system. Seasonal changes affecting the air temperature and the water table level may occur, and affect the magnitude and pattern of the thermal anomalies. However, Teschner et al. (2007) reported seasonal changes on the order of $\sim 5^{\circ} \mathrm{C}$ at nearby fumarole. This suggests that the changes are negligible for our purpose. Moreover, at Nisyros the fumarole temperature outlet does not change on a day-to-day basis (Teschner et al., 2007), at least when the volcano is quiescent. Consequently we consider that the IR data, based on single day recording, are representative of the site and of the activity during the encompassed period. Besides, we observe that the geothermal fields appeared (in the IR data) almost identical in 2010 and 2013. Therefore we are confident to relate IR data collected in 2010 to the soil analysis of samples collected in 2013. Indeed, considering the deposition processes, we do not observe geological/geomorphological evidence indicating clear changes in sedimentation, neither at fast rates (e.g., recent slumpings) nor at slow rates (e.g., upward grain-size changes) (Fig. 6). Also, we do not expect changes in sedimentation near mud pools, because the pits drain the surface runoff rather than acting as springs. Despite the flooding in this area preventing us from imaging parts of the crater floor in 2013, we expect temporary cooling of the water and the soil at the pits because of the mixing of rising hot gasses with large volumes of cold rain water. This phenomenon possibly explains the disagreement between the granular aspect of S06 and the low temperature at that location. Limitations may also arise from the infrared technique, the environmental conditions, the image processing and mosaicking, or a combination thereof. Moreover, soil sampling and laboratory analysis may affect the conclusions drawn, as detailed below.

\subsubsection{IR imaging}

One of the main limitations affecting IR imaging relates to the changes in emissivity and transmittance, which depend on geometric conditions (i.e., on distance and viewing angle, and on the physical condition of the target and of the atmosphere). Here we detail the limitations encountered at Nisyros and their influence on the results. A detailed description of general limitations is provided by Spampinato et al. (2011). 
The IR mosaics we present are computed using a constant camera position. However, $D$ changes within a single image and across each set of images from foreground to background, and $T_{\mathrm{obj}}$ is expected to vary consequently. In our data set we found that, doubling $D$, the $T_{\text {obj }}$ varies in the range of 1-3\% according to the occurrence of $T_{\mathrm{obj}}$ close to or higher than $T_{\mathrm{atm}}$. For the processing, we use the mean distances in the field of view. Therefore the temperature is expected to be overestimated at shorter distances. We note that these differences are small and therefore negligible for the purpose of this study. Moreover, $D$ influences the geometric and thermal resolutions. Increasing $D$ has the effect of widening the pixel size and lessening the apparent temperature, because the pixel will include, comparatively, more cold surface than degassing vents. This also leads to a lower sensitivity in the detection of apparent temperature contrasts. Further errors arise from assuming a single emissivity value, because it changes with the material and the viewing angle (Ball and Pinkerton, 2006). We use $\varepsilon=0.93$ for the average site conditions following previous works (Lagios et al., 2007). Laboratory tests showed that emissivity is expected to decrease as the viewing geometry deviates from the perpendicular to the surface (Ball and Pinkerton, 2006). Such a phenomenon should affect the crater floor due to the oblique viewing, but it should not affect the flanks, as the viewing geometry is almost perpendicular. Nevertheless we do not observe any temperature gradient that may relate to the viewing angle. Another issue related to the site conditions is the presence of steam in the line of sight, which dampens the propagation of the thermal signal (Sawyer and Burton, 2006). As shown by the digital panoramas (Figs. 2a, 3a and c), we managed to collect our IR data during low-to-absent (visible) steam output, although we cannot rule out its contribution.

Considering the atmospheric conditions, we corrected the transmittance using values of temperature and relative humidity suitable for the site conditions. This does not affect our results because the purpose of this work is to investigate the spatial distribution of thermal anomalies. Indeed, we tested that changes in $T_{\mathrm{atm}}$ of $\pm 10^{\circ} \mathrm{C}$ cause variations of $T_{\mathrm{obj}}$ ranging between 3 and $1{ }^{\circ} \mathrm{C}$ for cool ground and $<1{ }^{\circ} \mathrm{C}$ for heated ground.

Finally, in terms of data processing, the georeferencing appears accurate along the flank because there are matching features (layering) between hand-held IR and satellite OP images, as well as only a small amount of geometric distortion. We did not further analyze the accuracy of georefencing; at the crater floor this accuracy may be lower because of the lack of recognizable features. Moreover, the IR images taken from the crater floor may suffer from large geometric distortion due to the viewing geometry. However, since our data are actually collected from a short distance (a few hundred meters) with a lens providing a field of view of $24^{\circ} \times 18^{\circ}$, which is somewhat narrow, large distortions are consistent.

\subsubsection{Soil analysis}

Soil samples were collected within the top $50 \mathrm{~cm}$ only. Sampling at a different depth might provide different information because we commonly observe an increase in alteration and crystallization at the interface of lithological beddings. However, we are confident that the correlation of grain size with the IR data is beyond coincidence.

Grain-size distribution of volcanic deposits is generally investigated to understand eruptive processes and energy (Brazier et al., 1983) or to address the permeability of volcanic deposits (Peltier et al., 2012). A major limitation during our sieving operation was in the artificial modification of the grain-size distribution. That is, in our samples, native sulfur crystals and chemically weathered volcanic clasts (Fig. 7) were fragile and could break into smaller granular particles. Conversely, the cohesive material appears as aggregates simulating granular clasts. We attempted to minimize these issues with a careful washing to avoid strong particle collision and by using a brush to disperse the cohesive aggregates. The substantial difference in sand contents between the granular and cohesive type (Fig. 6) suggests that our sieving procedure prevented the convergence to a single sand class. Another source of error affecting the fraction distribution derives from having volcanic silicate particles with a density of 2.4-2.6 $\mathrm{g} \mathrm{cm}^{-3}$ mixed with native sulfur crystal of $1.9 \mathrm{~g} \mathrm{~cm}^{-3}$ density. The density contrast could cause a $7 \%$ difference in weight on equal volumes of silicate and sulfur, but as the quantity of silicate in our samples is much larger, the bias becomes negligible.

A systematic bias in the grain-size description of the soil would cause a different or even misleading estimation of permeability values and consequently affect the interpretation of the thermal field. We might have overestimated the amount of gravel and coarse sand by having the largest sieve mesh at $2.0 \mathrm{~mm}$ and by fixing the maximum $d<10 \mathrm{~mm}$ based on visual description. We evaluate this effect to be $\sim 10 \%$ for the cohesive type and up to $\sim 20 \%$ for the granular type ( $\sim 40 \%$ for S01). This error affects only the relative percentage of granular fractions, not the relative percentage of granular vs. cohesive, though we disregarded the occurrence of gravel to estimate the soil permeability. The permeability can be measured by laboratory or in situ tests, but both the procedures are technically demanding for our purpose (Lambe and Whitman, 2008). Alternatively, empirical formulae based on particle size distribution can be used. We applied the formulation of Alyamani et al. (1993) to the granular samples. The permeability values of samples S01 and S06 are based on real grain-size data (Fig. 7). The permeability values of samples S07, S08, S09, S10, and S12 required a strong assumption about the minimum grain diameter and its mass percentage. Nevertheless, all the estimated permeability range corresponds to tabulated values (Bowles, 1988) and thus are reasonable. We also tested that the permeability remains in the same order of magnitude when the mass percentage of the 


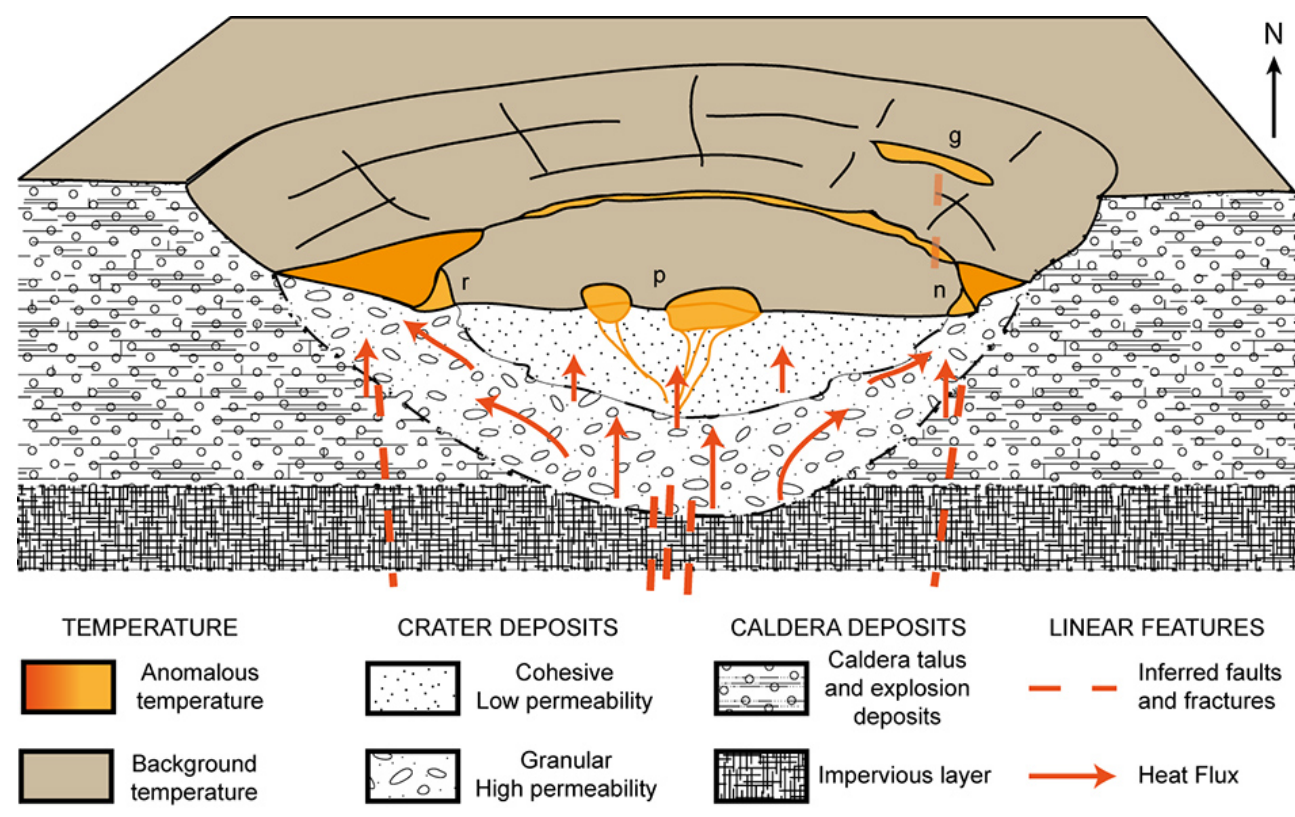

Fig. 8. Sketch (not to scale) of the conceptual model. At the bottom an impervious layer is broken by faults that drive the phreatic explosion through the caldera talus and the deposits of an older eruption. On top of the impervious layer is the crater. The heat rising from the depths enters the crater through the faults and propagates upward. According to our hypothesis, the crater is initially filled by granular and permeable deposits that progressively appear only at the sides. Later cohesive and impermeable material deposits on top of and in heteropy to the coarse ones. The heat flux rises with different efficiency: high in granular deposits (longer arrows), low in cohesive deposits (shorter arrows). Because of the low permeability at the crater center, fluids are forced to move sideways, increasing the degassing at the border. Possibly there are also other sideways faults that enhance the heat release at the NW and SE sites (r, n) and funnel hot fluids higher along the NE flank (g). Fault(s) at the crater center are also responsible for drainage and erosion of the crater filling, by which finally mud pits generate (p). At the surface, the thermal anomalies are presented in light and dark orange to indicate temperature differences. Brown is the cool terrain corresponding to the background temperature.

minimum grain diameter increases ten times. This suggests that permeabilities in the range of $10^{-5}-10^{-7} \mathrm{~ms}^{-1}$ are realistic for the granular soils in the Stefanos crater. Note that the values refer to water permeability, whereas air permeability, which is generally higher (Springer et al., 1998), should be considered. This approximation is nevertheless considered representative of the different behavior of the soil types identified at Stefanos.

\subsection{Conceptual model}

The Stefanos crater has an explosive phreatic genesis and is elongated NE-SW, consistent with a major fault trend observed elsewhere on the island (Caliro et al., 2005; Tibaldi et al., 2008). Marini (1993) suggested that a fault may have initiated the cratering by (i) connecting two aquifers and causing the flashing of the fluids, or (ii) weakening/opening the sealing of a deep, over-pressured, hot aquifer that flashed. One may assume that hot fluids continue to migrate upward through the fault into the crater (Fig. 8). In this scenario, we would expect to observe a linear thermal anomaly consistent with the trace of the fault trend. Our data, instead, show a near-circular thermal anomaly mainly at the border of the crater. Therefore faults are not the major control on the nearsurface expression of the heat flux.

Our soil analysis suggests that (i) cohesive and impervious material seals the center of the crater and thus inhibits the convective fluid ascent, which is then diverted and forced laterally toward the crater border. (ii) There, granular and permeable materials effectively transfer the heat along the crater border. Indeed, we found a permeability contrast of three orders of magnitude in the granular material only. Combined with cohesive material, our study suggests a contrast of up to six orders of magnitude. Consequently, the heat release appears to be controlled by the soil texture distribution. The soil type, in turn, is related to depositional processes (Fig. 8). The depositional processes are initiated with rockfalls and landslides. The remobilized material corresponds to the original talus of the caldera escarpment and to the deposits of the Kaminakia and Stefanos explosions. Afterwards, mixed granular and cohesive sediments drained by the superficial runoff into the crater from the surrounding relief and gradually filled the crater (Fig. 8). We observe that the soil particles range from pebbles to silt/clay and that there is a selective deposition based on the energy of the runoff; the particles travel 
either short or long distances from the crater rim according to their dimension.

The IR observations indicate that the western, southern and eastern borders have a wider extent of the thermal anomaly, which might relate to a more widespread deposition of granular material. We conjecture that the sediment input at those sites is larger because of the adjacent highs in relief, the Lofos dome and the caldera rim (Fig. 1b), whereas in the north the topography is flat (Lakki plain in Fig. 1b).

Only the local mud pools and the diffuse heating along the northern flank ( $\mathrm{p}$ and $\mathrm{g}$ in Figs. 3-5) contrast the lithological control and can be speculatively attributed to the volcanotectonic control. Buried and inactive fractures can drain the finer fraction of soils opening large or small permeable channels.

\subsection{Comparison with other results}

\subsubsection{Thermal data}

The comparison of our ground-based survey with previous satellite-based observations (Lagios et al., 2007) can only address the spatial distribution of the thermal anomalies and not the amplitude. This is because the geometric resolution differs by two orders of magnitude and therefore the thermal resolution is different. Moreover, the observation angle from our view point favors accurate thermographic imaging of the flank, whereas satellites have a better view of the crater floor. Nevertheless, both data sets reveal that the southern sector of the crater shows a more pronounced thermal flux than the northern sector. Prior to the present study, only a single ground-based IR survey had been performed at Nisyros (immediately after an episode of unrest in 2002) with the aim of validating satellite IR data (Lagios et al., 2007). Images were collected from the caldera rim at Nikia (Fig. 1) and showed all of the Stefanos crater except for the eastern flank and the surrounding floor. The spatial resolution of the previous survey is one order of magnitude lower than the resolution of our images. Considering this difference, the amplitude of the anomalies still appears in the same range of values, and the spatial pattern has remained similar. Only small anomalies within the current cold region and in the proximity of the upper crater rim have disappeared since 2002. That might indicate a small decrease in activity following the unrest and simultaneously exclude a significant decline in heat flux since 2002. The general pattern of temperature distribution remains mostly constant. The anomaly at the crater floor occurred where we expect the deposition of cohesive sediment, thus confirming our hypothesis on the depositional sealing. The comparison of our 2010 and 2013 surveys, where possible, also does not show significant change in the extent of the thermal field, confirming the stability of the degassing system and suggesting that depositional sealing acts at a low rate.

\subsubsection{Lithological control}

At Nisyros we describe the thermal field of the Stefanos crater and the concurrence with the soil texture causing permeability contrasts on the order of $10^{4}-10^{6} \mathrm{~ms}^{-1}$. The role of soil texture in controlling the thermal permeability was also suggested at White Island, New Zealand (Mongillo and Wood, 1995), where lacustrine sediment and fractured lavas control the distribution of fumarole or thermal anomalies. At Yenkahe, Vanuatu (Peltier et al., 2012), differences in soil permeability and thermal expression were observed involving scoria layers and ash layers. Whereas at these two sites the permeability contrasts are inherited mostly from primary eruptive products and processes, at Stefanos it is inherited from sedimentary depositional processes. A temporal development of sediment accumulation and, accordingly, a temperature field change at volcanic craters is open for speculation. In the first stage, we suspect the occurrence of crater inward sliding of peripheral blocks as observed at Anatahan, Northern Mariana Island (Nakada et al., 2005) and at Miyakejima, Japan (Geshi et al., 2012). In a later stage, the crater collects sediments through ephemeral fluvial-todeltaic depositional processes, which activate with seasonal rainfalls. Our work hence suggests that permeability contrasts generated by depositional processes may be relevant for the evolution of the fumarole field elsewhere, possibly even being independent from the crater's genesis. Any process reducing the soil permeability (e.g., compaction, argillification) or increasing the conductive loss (e.g., increased sediment thickness) might be a factor of risk, because, while reducing the appearance of the heat signature, it also contributes to the seal the hydrothermal system. The sealing of hydrothermal sources may lead to overpressure in the hydrothermal system, facilitating phreatic explosions (Marini et al., 1993).

\subsubsection{Structural control}

While the role of soil texture has been generally underestimated, many previous studies at White Island, New Zealand (Mongillo and Wood, 1995), at Etna, Vulcano, and Stromboli, Italy (Finizola et al., 2003; Aubert et al., 2008), at Kudryavy, Kurili islands (Yudovskaya et al., 2008), and Yenkahe, Vanuatu (Peltier et al., 2012) identified and attributed the thermal anomalies to tectonic fault planes or crater border facilitating the migration and escape of fluids. These discontinuities may have a geomorphologic expression at the surface or may be buried.

At the Nisyros caldera the elongation of the crater's major axis, the structural data and $\mathrm{CO}_{2}$ flux measurements indicate that tectonics exert a strong control on fluid pathways (Caliro et al., 2005). Fractures are identified crosscutting the southern flank of the Stefanos crater (Caliro et al., 2005). These fractures are expected to control the fluid flow at depth, whereas at a shallow level their directional permeability may 
be overprinted by the soil distribution, which pervasively distributes the thermal expression. Indeed, we observed that the wider thermal features lie parallel to the fracture direction, but we do not recognize a well-defined linear thermal pattern. Also, the gas flux measured during the unrest in 1999-2001 appeared almost homogeneously distributed across the crater (Caliro et al., 2005), which may result from the enhanced activity level. Nevertheless, there are two more pieces of evidence, the boiling ponds and the thermal anomaly along the northern flank ( $\mathrm{p}$ and $\mathrm{g}$ in Figs. 3, 4, and 7, respectively), suggesting that fractures occur in the subsurface and locally influence the thermal field.

\subsubsection{Stress control}

Previous authors have also studied the influence of the gravitational stress field on fluid uprise (Schöpa et al., 2011). We address this topic at Nisyros only qualitatively because the topography of the Stefanos crater is minor. The crater is excavated $\sim 30 \mathrm{~m}$ below the mean caldera topography, and little is known about the mechanical parameters of the sediments. A suitable analogue for this morphology is represented by open pit mines, so we can adopt results from such studies (Stacey et al., 2003) to our case study. Firstly, the stress field generated by opposite topographic reliefs does not interact when the distance of the reliefs is 0.8 times their height. At Nisyros, this condition is met both at the scales of the caldera and of the Stefanos crater. Secondly, close to the surface, the trajectories of the maximum principal stress $(\sigma 1)$ follow the topography, being near-vertical at the crater walls and horizontal at the crater floor (Stacey et al., 2003). Similarly, another study about the stress field inside a crater morphology suggests that maximum horizontal stresses are compressive on the crater floor (Schöpa et al., 2011). This may explain the absence of thermal degassing and thermal anomalies in the crater floor at Vulcano Island (Schöpa et al., 2011). However, an important difference exists between the two sites; at the crater floor of Stefanos the thermal anomalies are clearly expressed, whereas at Vulcano thermal anomalies are seen in the crater floor.

\subsection{Implications for future studies}

We think that additional case studies might improve the description and quantification of the geological factors influencing fluid flow in geothermal areas. While the present study introduced additional complexities to be considered when inferring deeper geological settings from thermographic data, repeated surveys can witness the evolution of the fumarole field. The thermal field of some volcanoes, e.g., Vulcano Island, Iwodake, and Colima (Harris and Maciejewski, 2000; Matsushima et al., 2003; Stevenson and Varley, 2008) have experienced temporal and spatial changes. Such changes are common in active volcanic and geothermal settings and our results suggest that the observation and moni- toring of lithologies, fault and fractures, and stresses can improve the understanding of those changes. We propose that thermal anomalies may be reduced by the additional deposition of sediments acting as an insulating layer; conversely, a removal of material should augment the appearance. The deposition or removal of large volumes may be associated with structural changes such as faulting, landslide or with eruptive processes, which have the potential to modify the degassing and thermal anomaly.

From a technical perspective, the interpretation of thermal fields benefits from the integration of IR imaging and geological information. GIS-based analysis finally allows us to generate historical databases that easily integrate different information. This would undoubtedly benefit the hazard assessment by improving the interpretation of infrared data in terms of increased activity or increased permeability.

\section{Conclusions}

We used IR measurements to map the spatial arrangement of the thermal field at the phreatic crater of Stefanos on Nisyros Island (Greece). The combination of IR images and soil grain-size analysis suggests that the temperature field is influenced by depositional processes as well as structural features such as faults. Warmer areas occur near the edge of the crater floor within permeable soil, while colder areas occur within the cohesive sediments at the center. Localized thermal anomalies might be associated with local or islandwide fractures, with increased erosional propensity. Consequently, three main factors control fumarole activity: lithology (Peltier et al., 2012, this study), volcanotectonic structures (Finizola et al., 2003), and the stress field (Schöpa et al., 2011). The relative importance of these three main players may change from site to site. Assuming that permeability changes control the thermal field at the surface, thermal mapping might allow us to assess the permeability setting of the near subsurface. We suggest that the parameters controlling the fumarole sites might be applicable elsewhere, though their hierarchy and efficiency may vary according to the genesis of the volcanic morphology and the surrounding geological setting.

Acknowledgements. We gratefully acknowledge A. Klatten, E. Günther, M. Ramatschi and K. Wiencke for help and support during the various field campaigns, and $\mathrm{M}$. Zahariadis for logistic support on the island. We thank G. Frijia and C. Fisher for the provision of the laboratory facilities and materials at the University of Potsdam. Detailed reviews by D. Pyle and H. Kinvig, and by the Topical Editor, Y. Lavallee, are acknowledged. Financial support by GFZ Potsdam, the Helmholtz Initiating and Networking award, and the Helmholtz EOS-2 program are greatly appreciated.

The service charges for this open access publication have been covered by the GFZ German Research Centre for Geoscience Helmholtz Association.

Edited by: Y. Lavallee 


\section{References}

Alyamani, M. S. and Zekâi, Ş.: Determination of Hydraulic Conductivity from Complete Grain-Size Distribution Curves, Groundwater, 31, 551-555, 1993.

Ambrosio, M., Doveri, M., Fagioli, M. T., Marini, L., Principe, C., and Raco, B.: Water-rock interaction in the magmatichydrothermal system of Nisyros Island (Greece), J. Volcanol. Geothermal Res., 192, 1, 57-68, 2010.

ASTM-D6913-04: Standard Test Methods for Particle-Size Distribution (Gradation) of Soils Using Sieve Analysis, Am. Soc. Test. Materials, 6913-04, doi:10.1520/D6913-04R09, 2009.

Aubert, M., Diliberto, S., Finizola, A., and Chébli, Y.: Double origin of hydrothermal convective flux variations in the Fossa of Vulcano (Italy), Bull. Volcanol., 70, 743-751, 2008.

Ball, M. and Pinkerton, H.: Factors affecting the accuracy of thermal imaging cameras in volcanology, J. Geophys. Res. Solid Earth, 111, B11203, doi:10.1029/2005JB003829, 2006.

Benson, C. H. and Trast J. M.: Hydraulic conductivity of thirteen compacted clays, Clays Clay Min., 43, 669-681, 1995.

Bowles, J. E.: Foundation analysis and design, McGraw-Hill Book Company Limited, England, 1988

Brazier, S., Sparks, R. S. J., Carey, S. N., Sigurdsson, H., and Westgate, J. A.: Bimodal grain size distribution and secondary thickening inait-fall ash layer, Nature, 301, 115-119, 1983.

Bukumirovic, T., Italiano, F., and Nuccio, P.: The evolution of a dynamic geological system: the support of a GIS for geochemical measurements at the fumarole field of Vulcano, Italy, J. Volcanol. Geothermal Res., 79, 253-263, 1997.

Caine, J. S., Evans J. P., and Forster C. B.: Fault zone architecture and permeability structure, Geology, 24, 1025-1028, 1996.

Caliro, S., Chiodini, G., Galluzzo, D., Granieri, D., La Rocca, M., Saccorotti, G., and Ventura, G.: Recent activity of Nisyros volcano (Greece) inferred from structural, geochemical and seismological data, Bull. Volcanol., 67, 358-369, 2005.

Chiodini, G., Brombach, T., Caliro, S., Cardellini, C., Marini, L., and Dietrich, V.: Geochemical indicators of possible ongoing volcanic unrest at Nisyros Island (Greece), Geophys. Res. Lett., 29, p. 16, doi:10.1029/2001GL014355, 1759.

Chiodini, G., Cioni, R., Leonis, C., Marini, L., and Raco, B.: Fluid geochemistry of Nisyros island, Dodecanese, Greece, J. Volcanol. Geothermal Res., 56, 95-112, 1993.

Chiodini, G., Vilardo, G., Augusti, V., Granieri, D., Caliro, S., Minopoli, C., and Terranova, C.: Thermal monitoring of hydrothermal activity by permanent infrared automatic stations: Results obtained at Solfatara di Pozzuoli, Campi Flegrei (Italy), J. Geophys. Res. Solid Earth, 112, B12206, doi:10.1029/2007JB005140, 2007.

Dobson, P. F., Kneafsey, T. J., Hulen, J., and Simmons, A.: Porosity, permeability, and fluid flow in the Yellowstone geothermal system, Wyoming, J. Volcanol. Geothermal Res., 123, 313-324, 2003.

Dozier, J.: A method for satellite identification of surface temperature fields of subpixel resolution, Remote Sens. Environ., 11, 221-229, 1981

Faulkner, D. R., Jackson C. A. L., Lunn R. J., Schlische R. W., Shipton Z. K., Wibberley C. A. J., and Withjack M. O.: A review of recent developments concerning the structure, mechanics and fluid flow properties of fault zones, J. Struct. Geol., 32, 15571575,2010
Finizola, A., Sortino, F., Lénat, J.-F., Aubert, M., Ripepe, M., and Valenza, M.: The summit hydrothermal system of Stromboli. New insights from self-potential, temperature, $\mathrm{CO}_{2}$ and fumarolic fluid measurements, with structural and monitoring implications, Bull. Volcanol., 65, 486-504, 2003.

Ganas, A., Lagios, E., Petropoulos, G., and Psiloglou, B.: Thermal imaging of Nisyros volcano (Aegean Sea) using ASTER data: estimation of radiative heat flux, Internat. J. Remote Sens., 31, 4033-4047, 2010

Geotermica Italiana: Nisyros 1 geothermal well, PPC-EEC report, p. $160,1983$.

Geotermica Italiana: Nisyros 2 geothermal well, PPC-EEC report, p. 44, 1984.

Geshi, N., Acocella, V., and Ruch, J.: From structure- to erosioncontrolled subsiding calderas: evidence thresholds and mechanics, Bull. Volcanol., 74, 1553-1567, 2012.

Gottsmann, J., Carniel, R., Coppo, N., Wooller, L., Hautmann, S., and Rymer, H.: Oscillations in hydrothermal systems as a source of periodic unrest at caldera volcanoes: Multiparameter insights from Nisyros, Greece, Geophys. Res. Lett., 34, L07307, doi:10.1029/2007GL029594, 2007.

Gottsmann, J., Rymer, H., and Wooller, L.: On the interpretation of gravity variations in the presence of active hydrothermal systems: Insights from the Nisyros Caldera, Greece, Geophys. Res. Lett., 32, L23310, doi:10.1029/2005GL024061, 2005.

Graton, L. C. and Fraser, H. J.: Systematic packing of spheres: with particular relation to porosity and permeability, J. Geol., 43, 785909, 1935.

Hardee, H.: Permeable convection above magma bodies, Tectonophysics, 84, 179-195, 1982.

Harris, A. and Maciejewski, A.: Thermal surveys of the Vulcano Fossa fumarole field 1994-1999: evidence for fumarole migration and sealing, J. Volcanol. Geothermal Res., 102, 119-147, 2000.

Harris, A. J., Lodato, L., Dehn, J., and Spampinato, L.: Thermal characterization of the Vulcano fumarole field, Bull. Volcanol., 71, 441-458, 2009.

Kinvig, H. S., Winson, A., and Gottsmann, J.: Analysis of volcanic threat from Nisyros Island, Greece, with implications for aviation and population exposure, Nat. Hazards Earth Syst. Sci., 10, 1101-1113, doi:10.5194/nhess-10-1101-2010, 2010.

Lagios, E., Vassilopoulou, S., Sakkas, V., Dietrich, V., Damiata, B., and Ganas, A.: Testing satellite and ground thermal imaging of low-temperature fumarolic fields: The dormant Nisyros Volcano (Greece), ISPRS J. Photogram. Remote Sens., 62, 447-460, 2007.

Lambe, T. W., and Whitman, R. V.: Soil mechanics SI version, John Wiley\&Sons, 2008

Marini, L., Principe, C., Chiodini, G., Cioni, R., Fytikas, M., and Marinelli, G.: Hydrothermal eruptions of Nisyros (Dodecanese, Greece), past events and present hazard, J. Volcanol. Geothermal Res., 56, 71-94, 1993.

Matsushima, N., Kazahaya, K., Saito, G., and Shinohara, H.: Mass and heat flux of volcanic gas discharging from the summit crater of Iwodake volcano, Satsuma-Iwojima, Japan, during 19961999, J. Volcanol. Geothermal Res., 126, 285-301, 2003.

Mongillo, M. and Wood, C.: Thermal infrared mapping of White Island volcano, New Zealand, J. Volcanol. Geothermal Res., 69, 59-71, 1995 . 
Nakada, S., Matsushima, T., Yoshimoto, M., Sugimoto, T., Kato, T., Watanabe, T., Chong, R., and Camacho, J. T.: Geological aspects of the 2003-2004 eruption of Anatahan Volcano, Northern Mariana Islands, J. Volcanol. Geothermal Res., 146, 226-240, 2005.

Pantaleo, M.: Geothermal and deformation activity observed at volcanoes by using high resolution imaging, $\mathrm{PhD}$ Thesis, Mathematisch-Naturwissenschaftlichen Fakultat der Universitat Potsdam, 2014.

Papadopoulos, G. A., Sachpazi, M., Panopoulou, G., and Stavrakakis, G.: The volcanoseismic crisis of 1996-1997 in Nisyros, SE Aegean Sea, Greece, Terra Nova, 10, 151-154, 1998.

Parks, M., Caliro, S., Chiodini, G., Pyle, D., Mather, T., Berlo, K., Edmonds, M., Biggs, J., Nomikou, P., and Raptakis, C.: Distinguishing contributions to diffuse $\mathrm{CO}_{2}$ emissions in volcanic areas from magmatic degassing and thermal decarbonation using soil gas ${ }^{222} \mathrm{Rn}-\delta^{13} \mathrm{C}$ systematics: Application to Santorini volcano, Greece, Earth Planet. Sci. Lett., 377, 180-190, 2013.

Peltier, A., Finizola, A., Douillet, G. A., Brothelande, E., and Garaebiti, E.: Structure of an active volcano associated with a resurgent block inferred from thermal mapping: The YasurYenkahe volcanic complex (Vanuatu), J. Volcanol. Geothermal Res., 243/244, 59-68, 2012.

Revil, A., Finizola, A., Piscitelli, S., Rizzo, E., Ricci, T., Crespy, A., Angeletti, B., Balasco, M., Barde Cabusson, S., Bennati, L., Bolève, A., Byrdina, S., Carzaniga, N., Di Gangi, F., Morin, J., Perrone, A., Rossi, M., Roulleau, E., and Suski, B.: Inner structure of La Fossa di Vulcano (Vulcano Island, southern Tyrrhenian Sea, Italy) revealed by high-resolution electric resistivity tomography coupled with self-potential, temperature, and $\mathrm{CO}_{2}$ diffuse degassing measurements, J. Geophys. Res., 113, B07207, doi:10.1029/2007JB005394, 2008.

Sachpazi, M., Kontoes, C., Voulgaris, N., Laigle, M., Vougioukalakis, G., Sikioti, O., Stavrakakis, G., Baskoutas, J., Kalogeras, J., and Lepine, J. C.: Seismological and SAR signature of unrest at Nisyros caldera, Greece, J. Volcanol. Geothermal Res., 116, 19-33, 2002.

Sawyer, G. M. and Burton, M. R.: Effects of a volcanic plume on thermal imaging data, Geophys. Res. Lett., 33, L14311, doi:10.1029/2005GL025320, 2006.

Schöpa, A., Pantaleo, M., and Walter, T.: Scale-dependent location of hydrothermal vents: Stress field models and infrared field observations on the Fossa Cone, Vulcano Island, Italy, J. Volcanol. Geothermal Res., 203, 133-145, 2011.

Sekioka, M. and Yuhara, K.: Heat flux estimation in geothermal areas based on the heat balance of the ground surface, J. Geophys. Res., 79, 2053-2058, 1974.
Shepherd, R. G.: Correlations of permeability and grain size, Groundwater, 27, 633-638, 1989.

Shinohara, H., Kazahaya, K., Saito, G., Matsushima, N., and Kawanabe, Y.: Degassing activity from Iwodake rhyolitic cone, Satsuma-Iwojima volcano, Japan: Formation of a new degassing vent, 1990-1999, Earth Planets Space, 54, 175-186, 2002.

Spampinato, L., Calvari, S., Oppenheimer, C., and Boschi, E.: Volcano surveillance using infrared cameras, Earth-Sci. Rev., 106, 63-91, 2011.

Springer, D., Loaiciga, H., Cullen, S., and Everett, L.: Air permeability of porous materials under controlled laboratory conditions, Ground Water, 36, 558-565, 1998.

Stacey, T. R., Xianbin, Y., Armstrong, R., and Keyter, G. J.: New slope stability considerations for deep open pit mines, J. South African Inst. Mining Metall., 103, 373-390, 2003.

Stevenson, D. S.: Physical models of fumarolic flow, J. Volcanol. Geothermal Res., 57, 139-156, 1993.

Stevenson, J. A. and Varley, N.: Fumarole monitoring with a handheld infrared camera: Volcán de Colima, Mexico, 2006-2007, J. Volcanol. Geothermal Res., 177, 911-924, 2008.

Tassi, F., Vaselli, O., Papazachos, C. B., Giannini, L., Chiodini, G., Vougioukalakis, G. E., Karagianni, E., Vamvakaris, D., and Panagiotopoulos, D.: Geochemical and isotopic changes in the fumarolic and submerged gas discharges during the 2011-2012 unrest at Santorini caldera (Greece), Bull. Volcanol., 75, 1-15, 2013.

Teschner, M., Faber, E., Poggenburg, J., Vougioukalakis, G. E., and Hatziyannis, G.: Continuous, direct gas-geochemical monitoring in hydrothermal vents: Installation and long-term operation on Nisyros Island (Greece), Pure Appl. Geophys., 164, 2549-2571, 2007.

Tibaldi, A., Pasquarè, F., Papanikolaou, D., and Nomikou, P.: Tectonics of Nisyros Island, Greece, by field and offshore data, and analogue modelling, J. Struct. Geol., 30, 1489-1506, 2008.

Varley, N. R. and Taran, Y.: Degassing processes of Popocatepetl and Volcan de Colima, Mexico: Geological Society, London, Special Publications, 213, 263-280, 2003.

Vougioukalakis, G. and Fytikas, M.: Volcanic hazards in the Aegean area, relative risk evaluation, monitoring and present state of the active volcanic centers, Develop. Volcanol., 7, 161-183, 2005.

Yudovskaya, M. A., Tessalina, S., Distler, V. V., Chaplygin, I. V., Chugaev, A. V., and Dikov, Y. P.: Behavior of highly-siderophile elements during magma degassing: A case study at the Kudryavy volcano, Chem. Geol., 248, 318-341, 2008. 